Article

\title{
To Alleviate or Elevate the Euroamerican Genealogy Fever
}

\author{
Iain Riddell \\ School of Media, Communication and Sociology, University of Leicester, Leicester LE1 7LA, UK; \\ analysis@kinshipcollation.net
}

Received: 15 January 2018; Accepted: 6 March 2018; Published: 13 March 2018

\begin{abstract}
There has been a quiet cultural drift towards professionalism in genealogy over the last two decades. Developments in the UK on this subject have resulted in educational offerings that support professionalism through accountability to service consumers while a US debate has pushed for a recognised and regarded scholarship to underpin the professional genealogist. This article places the educational and learning needs of three broad groups of genealogists into the framework of the professional debate in its generality and genealogical specifics. With a concentration on the British context, the article considers the cultural-commercial signals and support offered to 'armchair enthusiasts'; the emerging models of professional education and formation aimed at lineage makers and the ongoing fractured models of scholastic genealogy. Looking ahead at educational needs, genealogy like other professions is now under threat from advances in artificial intelligence and algorithms, which could slice through the underpinnings of genealogical professionalism. The article concludes with a discussion of an alternative approach to genealogical education derived from the proposition that professionalism is to be found in the outputs and outcomes rather than the organisation of the practitioners of economic activity. From this stance, the needs of a full range of people pursuing genealogy can be addressed and their work informed by the developing understanding of Euroamerican kinship.
\end{abstract}

Keywords: genealogy; kinship; professionalism; AI

\section{Introduction}

Since the millennium, enabled by rapid digitisation of records, there has been a significant public interest in genealogy which has built on trends dating back to the 1980s noted by Maggie Loughran (Loughran 2009). In some quarters, as discussed by Hannah Little (Little 2007, pp. 89-112) this behaviour, has been described as fever and been linked to previous outbreaks in the nineteenth, eighteenth and even seventeenth centuries. There have been varied assessments of this current popular passion. James de Groot (De Groot 2006, pp. 391-13) has assessed it as a manifestation of a popular appetite to consume history. Ann-Marie Kramer (Kramer 2011, pp. 379-95) and Amy Holdsworth's (Holdsworth 2011) research has followed diverse subjects such as memory and emotion to understand genealogy's impact as a socio-cultural phenomenon that speaks to the current social landscape. The growth of genealogy engagement has resulted in the traditional genealogy culture focused on serving the needs of socio-political elites from the nineteenth century being subsumed within a genealogical search across a broader base of society. A consideration of the educational needs of the genealogically interested is complex, as neither genealogists nor the products of their genealogical endeavours can be or should be homogenised.

Academic socio-cultural investigations, of what is an absorbing hobby recognised as the fourth most popular use of the internet (Rodriguez 2014) skip over the other components of the genealogical cosmos. The armchair hobbyists have been fed and sustained by commercial-cultural interests; while 
others with a stake in genealogy have sought to create economic activity by meeting it, improving it and servicing parts of it. Genealogy has produced media and data-based products throughout the Euroamerican world manifest in books, TV programs, tools of genealogy and the digitisation of records. Meanwhile, the third interest group of genealogy, scholastic genealogists have sought to overcome a longstanding systemic academic resistance and disdain over the outputs of genealogical research (Mills 2003, pp. 260-77). In addition to the identification of the three types of people engaged in genealogy sketched above, there are considerations as to the doing of genealogy, as against the results of genealogical work, the cultural significance of it as a contemporary activity versus its historical perspective and historiographical utility.

The long extant network of genealogy built around local history and family centres and national organisations persists, but the advent of the 'armchair genealogy' through online providers of resources has created a large group with a reduced need for interaction with such bodies. Kate Friday (Friday 2012) has specifically explored whether the public's, notably this new mass group, ability to do genealogy has improved over time within the context of ever-increasing materials and resources. The rapid changes to both resources, materials and importantly the artificial intelligence built into the consumer-oriented companies make such assessments redundant on a regular basis. An education-based discussion, as to whether the change from collective, collaborative exchange of learnt skills and information shared in society meetings to individualistic endeavour based on active learning supported by an ever-improving AI has become valuable.

Such a debate gets to the heart of what a genealogist is, how they are defined and what they do, an area that has attracted not only Little but also Elizabeth Shown Mills (Mills 2003, pp. 260-77). Classification of and as genealogist includes self-identification and requires cultural context as well as differentiation between, leisure, occupation and professionalism, leading to complexity of sub-groups. Consideration is also required to understand the relationships between the sub-groups.

As a leading member of the US genealogical structures, Mills had a deep concern about the ongoing fractured relationship between historians, archivists and genealogists as the three descendant groups of nineteenth-century Antiquarianism. The latter group she regarded as being disrespected even while their work outputs were pillaged; in response to which, she stressed the need for genealogists to professionalise. It is hard to conceive of a means for any organised activity to become professional without a degree of learning and formal education, which is precisely the position that Mills took when she presented two pathways. Her preference was that genealogy should solidify its status through a greater concentration on relevance while conceding that professionalism could manifest through accountability.

This article weaves British response to the huge changes in who, how and why people are participating in genealogy as the weft, with professionalism as the warp. It considers the influences that have been brought to bear on the activity and its relationship to academia, through the lens of education and learning. In doing so, it will present how the diverse British genealogical establishment has focused heavily on professionalism through accountability. The review will suggest that a path forward lies not in compartmentalised professionalisms as per Mills' vision but in a wider multi-disciplinary endeavour (Herskovitz 2012, p. 5) that takes seriously David Moody's (Moody 1986) simple imperative that the outputs need to be more than lists of names.

The article will review the cultural challenges that swirl around those with a genealogical interest and extract the tensions that impact the development of an educational offering. The British perspective is contextualised by the broader Euroamerican environment as the cultural offering to enthusiastic hobbyists is explored before tackling the impact of the professional genealogist debate. As the defining trend of genealogy in recent decades has been technology, the article considers how participation has been revolutionised with a consequence for education and professional status. As genealogists are a diverse group, the article looks at how the outputs of genealogies sub-groups could be better supported by the academic world as partners. The review of educational needs concludes with 
a reframing of the debates by shifting the focus from identity as a genealogist to an offering based on outputs and outcomes of genealogy in an age of digitised mass participation.

\section{Feeding the Fever}

\subsection{Genealogy as Culture}

Mills' description of tree-climbers encompasses many internet users ensconced in their armchairs or at dining room tables collecting ever-expanding lists of names, but it would be an over assumption to say all. Mills' other categories of genealogists were lineage builders who assemble accurate facts in-depth around a lineage, potentially for economic recompenses and genealogical scholars working on the social history of how people lived. It is important to understand the learning offered to the tree-climbers by the other genealogists as mediated through the commercial-cultural entities, academia and genealogy establishment. To do this, four elements will be considered: learning by cultural osmosis as presented by the media and corporate entities; the framing of genealogy by ancestry.co.uk through its help, guidance and aides; the British professionalisation of genealogy through accountability and attempts by scholars to harvest from tree-climbers.

Jonny Vegas, a comedian with almost two decades of national level exposure on both BBC and ITV projects, who for a period advertised a leading brand of teabags, is a cultural figure with a certain reach. Since 2010 he has, on occasion used the media and social media to relate his experiences of Who do you think you are? WDYTYA? The thrust of his commentary, which emerged from research into his lineages, is that it was too boring to be made into a program and nobody until him had ventured beyond a few miles. 'Just got my file back from Who do you think you are? Not a single pirate or adventurer in my bloodline, not 1 \#gutted'. ${ }^{1}$ The cultural learning offered up here is that the history of the ordinary and hyperlocal does not interest, of course, this is the genealogical experience of discovery of the bulk of British people.

This one specific example should be contextualised by the approach of scotlandspeople.co.uk, a hybrid government-commercial genealogical resource base. The front page of the website on 26 October 2017, highlighted the following: Scottish authors in the 1935 valuation rolls; John Reith, 1st Baron Reith; Alexander Graham Bell; Margaret Henderson Kidd QC, each of which linked onto a discreet individual narrative illustrated with statutory records. These point to public-cultural learning that emphasises significance based on individuals of note and possibly, therefore, reflected glory.

Another of the commercial entities profiting from genealogy fever and serving both tree climbers, academics and lineage makers is the multi-national ancestry group which has digitised records from numerous jurisdictions and eras. For this substantial investment to produce revenue, the ancestry group also has to nurture the customers learning to maintain interest and subscriptions.

Once you've been bitten by the bug you'll find it hard to stop. Read these articles to discover expert research techniques and enjoy the hobby even more. ${ }^{2}$

This warning echoes the pathological debate above and also frames the relationship between expert advisors and hobbyist consumers. Such a definition of roles reinforces the themes that Mills critiqued in 2003 when applied in a cultural paintbrush across genealogy. A drive to be helpful and relevant leads commercial companies to offer tools and strategies.

Family Group Sheet-Each piece of information concerning a pedigree ancestor and his/her family is placed on a worksheet. Since the result of your research efforts will be to compile complete, correct and

\footnotetext{
@jonnyvegasreal, twitter.

Ancestry.co.uk, 'Help and Advice centre'. http:/ / www.ancestry.co.uk/cs/learning/Advice.
} 
connected families, the use of family group sheets from the beginning will make the compilation much easier.

This offering is heavy with laden terms that set and potentially limit expectation, for instance 'pedigree' which speaks of bloodlines, which in a society still pre-loaded with patriarchy directs attention to male lineages. Other commercial genealogy company advice directs the user to consider siblings and seek to discover the original names of brides. This entry level learning then is settled within an overall framing of genealogy as a series of nuclear-family households.

John Bullman's cultural output for the BBC's 'Secret History of the Family' relied upon genealogical work amassed by a team of researchers which stemmed from case studies identified by academics. ${ }^{3}$ The results, as presented by the descendants of the chosen historical egos, illustrated the osmosis learning in the cultural space. The language used by descendants linked the achievements of past generations to the bloodline, with personal qualities; therefore, flowing through to subsequent generations. ${ }^{4}$ Further, the desire to understand something about personal family history, how a family line links with large events or an inspirational ordinary past person overcoming adversity, as explored by Bullman's Spring 2016 series also produced an effective gateway to a wider appreciation of history. Improved engagement with the past that builds a wider knowledge base, being a positive outcome of the cultural interest in genealogy, was noted by Kramer in discussion with the Guardian when promoting her 2010 book.

Genealogy allows people to personalise the past, genealogists have told me: 'I hated history at school. It was just a series of dates with no connection to my life.' But then they've discovered that their great uncle won a medal during the First World War, and the place where he fought immediately becomes more than just another battlefield. ${ }^{5}$

The commercialisation of genealogy feeds upon the emotional desire to know 'who we are' through our family story 'See your research as your heritage and your story!' ${ }^{6}$ The impact of this being that their remains a genealogical output of narrative through story investigation that remains deeply personal and about individual identity. Kramer's identification of genealogists in her interview piece has to be taken widely and openly to be inclusive of tree-climbers, but those identified as generational scholars and lineage makers seem unlikely to subscribe to their genealogical work as 'their research, their heritage, their story'. So, it is time now to consider these groups and professionalism.

\subsection{Genealogist Profession}

When Little, as a professional archivist, adopted the hook of fever to frame her discussion of the intermeshing of family historians, archives and Scottish diaspora she recognised the pathological nature of the metaphor. It would not be a surprise if genealogists like Mills bristled at the enduring use of such descriptors; based on the opener to her 2003 paper.

We now stand at a threshold and face a critical choice. Are we content for other disciplines to dismiss genealogy as an "ego trip"-History Lite? Will we accept a role some others propose for us-that of Data Sweeper, mere drudge labor to boost the productivity of "real" historians?

She went on to identify that even on the occasions when historians stepped forward to pass positive light on the work of genealogists, it was often a backhanded compliment. The proffered cure for the condition was to educate the genealogist as a professional to bring them in line with historians and

3 Heather Shore. 'Telling Stories: From Artful Dodgers to The Secret History of My Family', 'Leeds Beckett University', 3 March 2016. http:/ / mediacentre.leedsbeckett.ac.uk/post/ telling-stories-from-artful-dodgers-to-the-secret-history-of-my-family/.

4 Joseph Bullman. 'The secret history of my family, the Gadbury sisters' BBC2, 10th March 2016; BBC Media Centre, 'Q\&A. with Joseph Bullman'. http://www.bbc.co.uk/mediacentre/latestnews/2016/secret-history-of-my-family.

5 Arnot.

6 http://www.ancestry.co.uk/cs/learning/TenCommonMistakes. 
archivists. The latter of which had undergone a process of professionalisation in recent decades. Mills' agenda from fifteen years ago was to develop generational history through a professionalisation based upon scholarship rather than accountability to consumers, as a means to draw distinctions between collectors of names, compilers of lineage references and scholars of how people lived as and through family networks.

As the discourse on professionalism, in general, is contentious enough in itself and the struggle to identify the markers of a historian from a professional historian in the minds of the public is equally amorphous, the struggle to conceptualise the notion of a professional genealogist for wide cultural consumption seems enormous. Mills' proposed definition placed great emphasis on education and learning

This proposed identity should distinguish our discipline from the gathering of names and creation of databases that has come to characterize "genealogy" in both popular and academic minds. Adopting the term, however, would carry responsibility ...

1. meet the historical profession's definition of "historian"—an individual with some formal education in history, who practices history through research or teaching;

2. possess earned credentials in genealogy (certification or accreditation) and, as such programs develop, pursue coursework and degrees in generational history;

3. publish their research in peer-reviewed journals whose essays meet the standards set for scholarship by the academic world

Noticeably, what underpins the prescription is a remedy that is focused on fixing the genealogist as the fever creates an environment in which they are disrespected. The deleterious elements she identified, a deep-rooted outmoded and outdated prejudice from academic history, actually infects the non-genealogist.

The status of qualified has become a linchpin of professionalism, and to be qualified requires the acquisition through education of certain skills (Thomas and Thomas 2014, pp. 38-55). The University of Strathclyde's MSc program timetable for Genealogical, Heraldic and Palaeographic Studies 2016-2017 provides a helpful insight into this paradigm. ${ }^{7}$ What emerges is a comprehensive offering of skill acquisition to be an effective and professional genealogist with a broad knowledge of sources and approaches to work on a variety of family-based and place-based studies. These skills are used by some program graduates to sell services to the public. The wider discourse on professionalism is vast and fractured in its own right; whether for lawyers, nurses or event managers (Watkins 1999, pp. 37-56; Hamilton 2011, p. 763). Debates rage over, should and could professionalism be formed past young adulthood, the dynamics of organisation and power, representation and defence of the collective. Rhodri Thomas and Huw Thomas from the perspective of tourism experts have critiqued the underlying ethos of professionalism, 'many occupations have sought to improve their status, material rewards and influence over public policy by attempting to professionalise.' They went on to question the closure of occupations by controlling entry into the newly formed professions and the primacy of influence over the content of the delivery of the profession. Certainly, such analysis holds true over Mills' preferred professionalisation of genealogy, how else will credentials have value unless adjudicated and rated?

Cultural evidence of the penetration of credibility into genealogical professionalism abounds.

Credentials - our researchers are handpicked, tested and trained to ensure they meet our unwavering commitment to quality. Our researchers possess four-year degrees in Family History and Genealogy, accreditations, or decades of experience, and share a passion for genealogy research. ${ }^{8}$

7 http://www.strath.ac.uk/media/ps/cll/cpd/docs/PG_Genealogy_Timetables_2016-17_1-year_final.pdf (accessed on 14 July 2016).

8 LegacyTree Genealogists. Available online: https://www.legacytree.com/services (accessed on 1 November 2017). 
I acknowledged overlaps with social and political history, but the trained genealogist in me always drew me back to the individuals in these big histories. It put the flesh on the bones. ${ }^{9}$

In a commercially sound fashion, it is embedded into spaces likely to be noticed by tree-climbers, often taking the form of lineage-maker genealogists seeking to monetise their skills, discussing courses from which they draw credentials. ${ }^{10}$ The question is whether, by design or by default, hobbyist tree-climbers have been exposed to the genealogical culture of professionalism that may have influenced perceptions.

\subsection{British Manifestation}

Within the British genealogical, cultural context, it is possible to identify Mills' lineage-makers. This group of a genealogist, the core of which consists of traditionalists whose background is within the district archives and local family history units includes some who seek to extract economic value from genealogy. The move to professionalise offered to this group has been serviced by a plethora of professional organisations in recent decades. For example, the Society of Genealogists (SOG), associated with the National Family History Centre through the Association of Genealogists \& Researchers in Archives, (AGRA) assesses portfolios of work. ${ }^{11}$ An alternative, the Register of Qualified Genealogists, (RQG), emphasises formal courses such as the University of Strathclyde's, Postgraduate Programme in Genealogical, Heraldic and Palaeographic Studies. ${ }^{12}$ The presentation of British genealogical professionalisation has gone down the route rejected by Mills in the US, accountability through accuracy. AGRA tells consumers

The report you receive from a professional genealogist should give details of the research you requested plus a description of the work carried out, including full references of any records consulted. Copies of relevant records are usually supplied. A conclusion and suggestions for further research should also be given. ${ }^{13}$

RQG stresses that its members,

Operating at post-graduate level they take already experienced, mature students and expose them to systematic methods of investigation and critical analysis of results so they can deliver quality outcomes from any research.

Graduates emerge with a good understanding of all relevant disciplines and with the confidence to tackle all aspects of even the most wide-ranging projects, and to report on findings clearly and succinctly.

A professional scholarly agenda though is more evident in the aims and objectives of RQG's peer-reviewed journal. The pressure of professionalism with a reliance on accredited learning, if not formal education was captured by James Hansen, a Mills collaborator in 2001. In the introduction to Professional Genealogy: A Manual for Researchers, Writers, Editors, lecturers and librarians, he stressed a distinction between experienced genealogists and the professional (Mills 2001).

A review of the online statements of organisations servicing the lineage makers and generational historians about professionalism reveals an ongoing conversation about quality. The centrality of quality service sits within a context of Thomas and Thomas' critique of professionalism. Such professionalism runs the risk of building a closed self-selecting hierarchy. As with the

9 Terry Bridger. 'A Genealogist of Distinction', AngliaResearch. Available online: https://www.angliaresearch.co.uk/articles/ a-genealogist-of-distinction/ (accessed on 1 November 2017).

10 'Professional Genealogy Educational Opportunities (National Institute)', Familysearch. Available online: https: / / www.familysearch. org/wiki/en/Professional_Genealogy_Educational_Opportunities_(National_Institute) (accessed on 1 November 2017).

11 http://www.agra.org.uk/join.

12 http://www.qualifiedgenealogists.org/accepted-qualifications.

13 http://www.agra.org.uk/research. 
development of other professions, there are very worthy and important intentions that drive professional education, learning and standards. The public ought to be assisted in knowing who is a medical quack and who is an eminent surgeon, what medicine is safe against which will kill you in the wrong dose. Establishing whose genealogical work on lineages has credibility and value for money is worthy but also has consequences.

\subsection{Before the Famine}

\subsubsection{Feast upon the Fever Repast}

Mills, as a leader of genealogical professionalism, had challenged that the products of her colleague's research could be and were procured by historians as a scholarly infringement. Such occurrences influenced her prescription for professionalisation in that scholarly genealogists should seek to define their profession through the peer-review publication of their work in journals dedicated to genealogy. These professionals should seek to benefit directly from their endeavours, in response to which historians, as fellow professionals, trained in the appropriate behaviours would have to reference the work outputs accurately. This article has suggested in response that the prescription was offered to the wrong party. In 2012, Arnon Hershkovitz, following an assessment of the status of genealogy and academia, presented an entirely different juxtaposition of academic genealogy.

Hershkovitz's view stressed how developments in the use of reconstructed genealogies had fed studies which focus on migratory patterns or the history of communities, rather than on individuals or families (Herskovitz 2012, pp. 7-10), Such developments are seen in the contemporary work of Klaus Hamberger (Hamberger 2016, p. 367) as well as Robert Ball and Patrick Beck's (Ball and Beck 2017) engagement with historical genealogy; and stray far from the classical genealogy of lineages and pedigrees. Within Britain, a few projects have used genealogical reconstructions to explore historical sociology, a prime example of which was the work of Cooper and Donald (Cooper and Donald 1995, pp. 257-78).

Their research used genealogy to understand the kinship basis of the servant-employee in the domestic setting, although on a such a small scale that it has been easy for historical demography to sideline their findings (Wall 2010, pp. 83-108). The pair worked up fresh genealogies to explore observations made by Davidoff and Hall as to the emerging middling class of late Hanoverian England. With only four case study family networks, the data used was minimal in comparison to what can be assembled more cheaply and efficiently today.

It is possible to observe that kinship played a role in the decisions of Thomas Minty and his wife, Isabella Wilken. The kin relationship not being between them and their servants but between the domestic staff. In their 1881 household were two sixteen-year-old female, first cousins, Margaret Cruickshank and Jane Christie, both from nearby economically precarious families. ${ }^{14}$ Only genealogical reconstruction reveals the connection and the connection opens up questions about kinship and society. Genealogy as a framework reveals connectivity; the analytical mindset is to switch the principal actor. This stance underlaid Lipp and Krempel's work on Esslingen, which used an 'analytical approach, which combines actor-centred perspectives' (Lipp and Krempel 2001, pp. 151-69, 155), and had a willingness to shift the central ego. An even more complex, illustration arises in Devon in the 1890s.

On census day 1891, Kate M. Lucas, an unmarried woman in her early twenties from Melksham district, Wiltshire was enumerated as a visitor to Mr and Mrs Day, Kingskerswell, Newton Abbot, Devon. It is impossible to know the quality and tone of the conversation held between the residents and enumerator, whether Kate herself spoke with the census taker or whether Mr Day entered into a rambling conversation or succinctly answered questions. What is clear is that visitor description

14 Ancestry.com, '1881 Scotland Census', Parish: Ellon; ED: 2; Page: 1; Line: 14; Roll: cssct1881_58. 
was considerably simpler than the actual relationship. Reconstruction of records identifies that young woman Kate Lucas's sister Rosina was the widow of the nephew of Mrs Day's paternal uncle's wife, and Rosina had since gone on to marry her deceased husband's young cousin; Mrs Day's mother's brother's wife was a cousin to both of Rosina's husbands.

By properly investigating and analysing a single data point, a snapshot of one evening linked Kingskerwell and Melksham in a chain of relationships that encompassed multiple locations in inner and urbanising outer London. Mr Day, a wine merchant himself had hailed from London, and the recovered relationships tumbled into the pleasure towns of Kent. The complex relationships between the Day and Lucas families swirled around a substantial late Georgian period inheritance built up by an early nineteenth century Dick Whittingtonesque figure. ${ }^{15}$

Just as with Cooper and Donald's assessment of related servants and householders, Rosina Lucas's marriages to two of these inheritors, relatives of Mrs Day, makes the presence of her sister at Kingskerwell highly unlikely to be coincident. The work to achieve such a web of relatives was hampered by the disaster of Rosina's 1891 enumeration in Kent. Rosina was listed by accident or by design as the eldest daughter of the Henry Biles family. Information which conflicted with the 1881 Biles family enumeration listing the eldest child a daughter with a different first name. This conflict required an in-depth and exhaustive exercise working with primary lists generated from births, marriages and death records. The task was to identify and refute other potential explanations. The exercise revealed that the eldest children of Henry Biles had both married young, the daughter in 1891 lived in Essex with her new familial unit and a son with his misidentified, older wife, Rosina and newborn child were resident in the parental family home. The output of the genealogical work was a reconstruction of the changing family units; the outcome of the effort was an appreciation of the movement and choices of the individuals. It was revealed that some members of this family had lived together, done business together, travelled, married, raised families, deserted their co-responsibilities, fallen out, disowned, never met, had written too, competed against, never know the other had existed.

The ability to reconstruct and interrogate large social networks of relatives is no longer limited to the grand families (Orr et al. 2008; Campbell 2003, pp. 310-11) but is an exercise that can be deployed across socioeconomic groups. Within these webs are many forms of families and many expressions of kinship. There are also many potential studies about hidden inter-relatedness and its impact on society, contextualised by treating kinship as a form of Bourdieu's social capital (Bourdieu 2011, pp. 81-93). These must generate a decision as to whether such studies are the province of genealogy, through generational historians or multi-disciplinary studies to which genealogists can contribute.

\subsubsection{Unwitting Contribution}

The outputs of genealogists, especially armchair enthusiasts, are being swept up and have become exploitable as a data source for studies that require a genealogical element. The driver for this being the commercial customer-based websites that have led to the digitisation of the records. Far in the past is the notion that only a small number of professionals required software for documenting genealogical reconstructions (Mills 2001, p. xxv), such interface is now a standard part of the customer experience. It is this and similar commercial developments, such as the offering of hints and the ability to make work public, that make genealogical endeavours readily raid-able. Over the last fifteen years, the appetite for genealogy has deepened and the consumerist technology has advanced to meet it. Indeed, a narrow range of commercial interests has co-opted much of the consumer base. Significantly, commercial genealogy and its customers rely on the voluntary sharing of knowledge within IT platforms. Technology could well be a significant challenge to professional genealogy and an appreciation of it and its role ought to be central to the learning offered to genealogy within

15 Phillip Lawton Sr., a freeman of the city of London, whose life can be tracked across newspapers, Old Bailey court records and his will and testament. 
a multi-disciplinary envelope. Mills, in 2001 noted how the development of consumer technology for the genealogy market had already uplifted the accuracy of the masses. She also used the rise of technology to forewarn that further changes would sweep through the genealogical world.

Consideration has to be given to the development of algorithms as further reducing the space for a traditional professional genealogy as a service. The artificial intelligence that has developed behind commercial offerings is being taught every second by the customers. Each time a record is linked to a name, every time a hint is reviewed, accepted and rejected, the ever-expanding database of digitised records is refined; in turn, the customer base is offered a slew of highly likely record matches in various parts of the interface.

The enduring Euroamerican fever for genealogy which has gone hand in glove with the internet has made the resources of genealogy more readily available. Consequently, the discovery of records and annotation are more reliable and the presentation more manageable. Now it is not only possible to simply raid the work of genealogist in the ways that Mills' found objectionable a decade and a half ago, but the mere exercise of building a web of interrelated people feeds off of the collective work of consumers. Artificial intelligence, as such, challenges genealogical professionalism in similar ways to that faced by medicine, the law and education (Chelliah 2017, pp. 1-3; Susskind and Susskind 2015). It would be an over claim to suggest that professional genealogy based upon accuracy and accountability of service will be famished by the lack of consumers, but it seems likely that a famine caused by the commercial offerings will restrict the market.

\section{Servicing the Fever}

\subsection{Handle with Care}

Genealogical endeavour is, of course, more than working with birth, marriages, deaths and enumeration records to build up lineages. For a minority of actors, there are further resources to be consulted; newspapers, charters and artefact books for clues and contextualization; the older these documents are, the more specialised skills are required. Professional genealogy, defined by certification, has rightly aimed to equip practitioners with these skills. It may need to be said that there is a trend also to digitise and database these resources. Thus, the antiquarian efforts of the nineteenth-century, published in only limited numbers, have become globally available through portals such as archive.org. The British Library still has less than ten percent of its Nineteenth-century British newspaper collection (NCBLNC) online, but the resource-size is already phenomenal. It is worth noting that the NCBLNC licences have been divided and packaged for consumption by two separate markets, one for the academic community the other pitched heavily at the genealogy fever. Whether this capitalisation of the product perpetuates a division between genealogy and academia, is born out of that division or illustrates the divide, is moot. What is clear is that their remains a divide between academia and other parties.

It is now over two decades since Mills, in frustration at genealogy's marginalisation, developed educational resources to equip professional genealogy and promoted the vehicle of scholastic genealogy, the generational historian. Her argument was to educate a strand of genealogists in such a fashion that it echoed the development of historians in the universities. Such specific specialisation draws upon only a single thread of the professionalisation argument and forces further compartmentalisation. In contrast, Herskovitz, who in principle agreed that genealogy could be an academic field, pointed toward collaboration through the positioning of genealogy as multi-disciplinary research (Herskovitz 2012, p. 7), Herskovitz based his call on an assessment of how genealogy is being interacted with, used and presented by different elements within academia.

However, academic genealogy is not merely an independent discipline, but rather a research field that juxtaposes many disciplines, like history, geography, literature, computer science, information science, linguistics. 
The Kindred Britain project is a useful example of this (Jenkins n.d.) ${ }^{16}$.

\subsection{Visualising Genealogy Outputs}

Kindred Britain, was a project to build a database of near 30,000 British egos that linked cultural actors across time and space. It was initiated by Nicholas Jenkins, a Stanford University expert of English Literature who sought to understand the cultural context of the creative arts through genealogy. The project was designed as a closed endeavour; the public cannot add additional people. The information science element of the project enables browsers to view the ego through ego-to-ego linkages, gain insights into locations and proximity. The database is not being updated and the data management systems, unlike other genealogy information projects such as GeneaQuilts (Bezerianos et al. 2010, pp. 1073-81) are not being made available.

Like Kindred Britain, GeneaQuilts, the TimeNet team (Kim et al. 2010) and the GenealogyVis (Liu et al. 2017) technology teams have relied upon genealogical work to develop their data visualisation tools. Consideration must be given as to whether these non-genealogist academics sought to usurp the work of those interested in genealogy or developed additional tools to be used to enhance genealogy outputs and outcomes. The consequence of either is exposed via the problem uncovered by the GenealogyVis team.

There have been many methods proposed to visualize the family trees. The most widespread visualizations are based on node-link diagrams, which focus on the layout of the family tree structure to explore the relationships among persons.

If the former is true, then genealogies on a large scale merely present a useful pre-built extensive and complex set of data to test proposed technology against for application elsewhere. If the latter is true and the systems are a useful addition to genealogy, then what is the purpose of being able to appreciate and analyse genealogies outside of the context of family domestic households and groups.

From an academic perspective, there are numerous traps associated with a display of genealogy as ego-to-ego relationships, family groups, family trees and even lineages. The consensus is that people participate in numerous families in their lifetimes, often simultaneously belonging to more than one constructed, imaginary family at the same time (Davidoff et al. 1998). Indeed, it has been long acknowledged that Euroamerican cultures have a loose $t$ and mish-mashed understanding of core terms such as kinship, family, relative, mother, father, uncle, and certainly cousin (Tadmor 2010, pp. 15-48; Segalen 1986; O'Day 1994). This creates uncertainty as to the very meaning of what is being accumulated by genealogical endeavours as the basic unit of society have shifted and changed.

Only over the courses of centuries, starting with the wealthy, has the family been transformed into a social institution that fostered the individual and the intimate person. (Amato 2008, pp. 326-33)

Unfortunately, Kindred Britain and other projects have overlooked the anthropological and continental European challenges to notions of Euroamerican kinship in their design concept. The GeneaQuilts team pointed to a classic conundrum of this, the idea of the family of England's Henry VIII. Both the product of a commercial genealogical company and GeneaQuilts would group the 1520-1540 Tudor Royals as a family, which is simply an unsustainable correlation with understandings in recent centuries. Therefore, genealogical education needs to be careful not to reinforce dubious notions of the family, patrilineage or bloodline in the public discourse. Joseph Amato was keen that it should be understood that the formed social institution of the family was preceded by concepts of different social belongings anchored to collectivity and locality. Amato challenged genealogists indiscriminately to, 'discard the regressive search for noble origins and pure lineages, we come to know ourselves literally as the makers of our family and the definers of family tradition.' This leaves the

16 http://kindred.stanford.edu/\#. 
following questions: What is genealogy if it is something other than the collecting of names, dates and interlinked egos? What is disguised by the fuzzy language of kinship, family, relatedness, cousin, mother, brother (Hirschfeld 1986, pp. 217-42), that those who practice genealogy can assist to resolve by interrogating their outputs?

The struggle to ascertain, describe and assert the meaning of these notions within a Euroamerican context is an ongoing conversation amongst historians and anthropologists, the outcomes of which have a profound impact on education for scholastic genealogy and genealogy as a multi-disciplinary juncture. What has loosely become labelled as Schneiderian anthropology (Schneider 1984; Shapiro 2016), a postulation that kinship is cultural and not biological (Schweitzer 2000; Sahlins 2013), has in the last four decades influenced studies that have drawn upon genealogical reconstructions. These efforts use genealogy, not as Maggie Loughran conflates it with family history (Loughran 2009), but as social networks that produce an advantage for individuals (Wellman and Frank 2001, pp. 233-73). Genealogical outputs, that break free of the various constraints of family, household, lineages and bloodlines, achieve outcomes that illuminate kinship as sociocultural capital. Sprawling webs of related people can be data-mined for connectivity as explored in the two case studies. The historians that supported the GeneaQuilts team provided them with a ged.com of 238 actors, which is minuscule especially as the system was predicated to handle up to 10,000 . The resource was large enough to showcase lineal connectivity to a line of inheritance but insufficient to expose 'that seemingly autonomous individuals and organisations are in fact embedded in social relations and interactions' (Brandes et al. n.d.) which is the heart of social network theory.

\section{Final Thoughts}

The educational needs of genealogists are revealed by a consideration of the outputs of their genealogical endeavours. For the armchair hobbyists who have been drawn down the rabbit hole of fascination, this may well be an appreciation of the changing nature of the family or an introduction to ideas about social networks and the nature of kinship. For the lineage-makers and those who produce materials for consumers of genealogy, an appreciation of the developments of AI and visualisation sciences appears to be essential. This should highlight the change it has exerted upon the profession and the potential it has created for enhanced outputs of professional genealogists. For scholarly genealogists with an academic outcome for their work, education ought to foster an appreciation of both the cultural tools they are working with and how they are forming sociocultural patterns with those tools. Also, the areas above should be covered in further depth.

Unresolved is the challenge to genealogists of how to reconcile that on the one hand their work is derided as unimportant aggrandisement while simultaneously being lifted by other scholastic professionals. Instead of making genealogists more acceptable to historians, the overall academia ought to have a focus on more equitable and collegiate relationships with the lineage-makers/commercial genealogists and generational scholars. This requires the genealogy establishments to have a firm sense of the outputs and outcomes of all layers of genealogical endeavour so that the fever of genealogy is elevated.

Tracing Mills and her co-travellers conversations with the corporations and developers in the early years of internet-expanded genealogy, it seems unlikely that they would have predicted the world of today. In this case, it is important to conclude with a brief consideration of the conflicts she highlighted, especially those that have been lost with an implication for genealogical learning. The phrases that stand out are, 'ego-trip', 'data sweeper' and 'lists of names'. Mills considered that genealogist had become synonymous with the notion of name gatherers. This function, whether good or bad, and it is clear that some genealogically interested people more than enjoy the accumulation, has now been usurped by the consumer servicing corporations who have purchased the digitisation rights. It is now the AI that seeks to efficiently hoover up and link together the lists. The concept of ego-trip is more nuanced. Kramer considered the public's encounter with genealogy as a gateway to history that leads them to more evocative and informative historical thought, while the Vegas example indicates 
that is not necessarily the case. The public feels the desire to consume a history of heroes and great men, seeking the adventurer and royal link rather than the wonder of a long-established community of networks. In such a cultural space, the idea of education for those interested in genealogy is important.

Deliberate avoidance of the term genealogist is worthwhile as the debate around who is a genealogist remains contentious. Note how Kramer identified genealogists inclusively in a way that Mills may well have found difficult a decade earlier. Who is to be educated and about what needs to informed by an appreciation of the nature and results of their genealogical endeavour rather than a blanket approach; the approach is to define and educate by outputs. See Table 1.

Table 1. Additional educational needs of genealogy based upon outputs of genealogical endeavour.

\begin{tabular}{|c|c|c|}
\hline Mills' Subgroups & $\begin{array}{l}\text { Subgroups Defined } \\
\text { by Outputs }\end{array}$ & Core Educational Concepts \\
\hline Tree-climbers & $\begin{array}{l}\text { Armchair builders of } \\
\text { vast webs }\end{array}$ & $\begin{array}{l}\text { - History is more than heroes and great men } \\
\text { - Leave behind notions of bloodlines and attributes } \\
\text { passed on through blood and sperm } \\
\text { - Working with genealogical Artificial Intelligence }\end{array}$ \\
\hline Lineage-makers & $\begin{array}{l}\text { Service providers and } \\
\text { producers of material for } \\
\text { the genealogy market }\end{array}$ & $\begin{array}{l}\text { - } \quad \text { Visualising beyond the family tree } \\
\text { - } \quad \text { Not all relationships are equally significant } \\
\text { The development of contemporary } \\
\text { genealogical culture } \\
\text { - } \quad \text { Appreciating and influencing the AI process } \\
\text { Shifting significance and dynamics of family }\end{array}$ \\
\hline Generational Historians & $\begin{array}{l}\text { Genealogy with } \\
\text { scholarly impact }\end{array}$ & $\begin{array}{l}\text { - } \quad \text { Beyond ego-to-ego and lists of relatedness } \\
\text { - } \quad \text { Debates as to the nature of Euroamerican kinship } \\
\text { - } \quad \text { Grappling with social capital based on networks } \\
\text { - Inserting actors into the framework of their webs } \\
\text { of relatedness to identify mutualities that } \\
\text { supported them as individuals }\end{array}$ \\
\hline
\end{tabular}

The modern world of digitisation and artificial intelligence presents a challenge to the notions of professionalism that genealogy has leant on for the last quarter of a century. The choice of the British genealogical community to seek professional validity through consumer service will continue to be undermined by the consumer genealogical services controlled by the large corporations. One response to this would be to extend the umbrella of professional, to include the global companies and structures that provision the genealogical market. Thomas and Thomas have identified this as a strategy taken by other modern professions as it notionally binds organisations to the collective of professional individuals. The drawback is that the power dynamics are shifted, further empowering large organisations.

These final thoughts seek to shift the ideas around education, particularly for those with a professional interest in genealogy, from personal identity to outputs. Consider how Mills sought to strengthen the hand of professional genealogy by the postulation of the generational historian, identified in line with the 'historian' as a means to rightly push back against 'historylite'. Over a decade later, the limited traction of this was evidenced by Fiona Fitzsimons, a Trinity College, Dublin linked, professional provider of genealogical services. ${ }^{17}$

17 Enclann, 'Meet the team', Fiona Fitzsimons. Available online: http:/ /www.eneclann.ie/about-eneclann/meet-the-team/ \#fiona (accessed on 28 November 2017). 
Genealogy is a branch of history and worthy of proper study, although this is still disputed by a majority of academic historians. (Fitzsimons 2013, p. 49)

The uncertain position and status that a professional education was meant to address for the genealogy of a scholarly character has not occurred within the British and Irish contexts. As the prescribed cure for marginalised genealogy was not directed at the pathology, the historian, but at its victim, the genealogist, the lack of progress is unsurprising. That other fields of academia are more than willing to put scholarly level genealogy at the heart of vast, sprawling projects ought to be inspiring. The challenge is then to develop genealogical education that produces outputs and outcomes through multi-disciplinary efforts that deepen knowledge of past and present societies.

Conflicts of Interest: The author declares no conflict of interest.

\section{References}

Amato, Joseph. 2008. Rethinking family history. Minnesota History 60: 326-33.

Ball, Robert, and Patrick Beck. 2017. Automatically Recreating Probabilistic History through Genealogy. Available online: https:/ / fhtw.byu.edu/static/conf/2017/ball-recreating-fhtw2017.pdf (accessed on 24 August 2017).

Bezerianos, Anastasia, Pierre Dragicevic, Jean-Daniel Fekete, Juhee Bae, and Ben Watson. 2010. GeneaQuilts: A system for exploring large genealogies. Transactions on Visualization and Computer Graphics 16: 1073-81. [CrossRef] [PubMed]

Bourdieu, Pierre. 2011. The forms of capital. Cultural Theory: An Anthology 1: 81-93. First published 1986.

Brandes, Ulrik, Linton C. Freeman, and Dorothea Wagner. n.d. 26.1 Social Network Analysis. Available online: http:/ / citeseerx.ist.psu.edu/viewdoc/download?doi=10.1.1.438.7600\&rep=rep1\&type=pdf (accessed on 7 September 2017).

Campbell, William H. 2003. A history of the clan Campbell, volume II: From Flodden to the restoration by Alastair Campbell of airds, A review. The Scottish Historical Review 82: 310-11. [CrossRef]

Chelliah, John. 2017. Will artificial intelligence usurp white collar jobs? Human Resource Management International Digest 25: 1-3. [CrossRef]

Cooper, Di, and Moira Donald. 1995. Households and 'hidden' kin in early-nineteenth century England: Four case studies in suburban Exeter, 1821-1861. Continuity and Change 10: 257-78. [CrossRef]

Davidoff, Leonore, Megan Doolittle, Janet Fink, and Katherine Holden. 1998. The Family Story: Blood, Contract and Intimacy. Harlow: Longman.

De Groot, Jerome. 2006. Empathy and enfranchisement: Popular histories. Rethinking History 10: $391-413$. [CrossRef]

Fitzsimons, Fiona. 2013. Is family history 'real' history? History Ireland 21: 49.

Friday, Kate. 2012. Learning from E-Family History: Online Research Behaviour and Strategies of Family Historians and Implications for Local Studies Collections. Ph.D. Thesis, Robert Gordon University, Aberdeen, UK.

Hamberger, Klaus. 2016. Relational sequence networks as a tool for studying gendered mobility patterns. Paper present at the International Conference on Sequence Analysis and Related Methods, Lausanne, Switzerland, June 8-10; pp. 367-381.

Hamilton, Neil. 2011. Fostering professional formation (professionalism): Lessons from the Carnegie foundation's five studies on educating professionals. Creighton Law Review 45: 763.

Herskovitz, Arnon. 2012. A suggested taxonomy of genealogy as a multidisciplinary academic research field. Journal of Multidisciplinary Research 4: 5.

Hirschfeld, Lawrence A. 1986. Kinship and cognition: Genealogy and the meaning of kinship terms. Current Anthropology 27: 217-42. [CrossRef]

Holdsworth, Amy. 2011. Television, Memory, and Nostalgia. Basingstoke: Palgrave Macmillian.

Jenkins, Nicholas. n.d. Originating Kindred Britain. Available online: http:/ /kindred.stanford.edu/notes.html? section=originating (accessed on 24 July 2017).

Kim, Nam Wook, Stuart K. Card, and Jeffrey Heer. 2010. Tracing genealogical data with TimeNets. Paper presented at the AVI 10, Rome, Italy, May 26-28. 
Kramer, Anne-Marie. 2011. Kinship, affinity and connectedness: Exploring the role of genealogy in personal lives. Sociology 45: 379-95. [CrossRef]

Lipp, Carola, and Lothar Krempel. 2001. Petitions and the social context of political mobilization in the revolution of 1848/49: A microhistorical actor-centred network analysis. International Review of Social History 46: 151-69. [CrossRef]

Little, Hannah. 2007. Archive fever as genealogical fever: Coming home to Scottish archives. Archivaria 64: 89-112.

Liu, Yuhua, Sicheng Dai, Changbo Wang, Zhiguang Zhou, and Huamin Qu. 2017. GenealogyVis: A system for visual analysis of multidimensional genealogical data. IEEE Transactions on Human-Machine Systems 47: 873-85. [CrossRef]

Loughran, Maggie. 2009. History of Genealogy/Family History 2009. Available online: http:/ /www.history.ac. uk/makinghistory/resources/articles/family_history.html (accessed on 20 July 2017).

Mills, Elizabeth Shown. 2001. Professional Genealogy. Baltimore: Genealogical Publ.

Mills, Elizabeth Shown. 2003. Genealogy in the "Information age": History's new frontier? National Genealogical Society Quarterly 91: 260-77.

Moody, David. 1986. Scottish Local History-A Introductory Guide. London: B.T. Basford.

O'Day, Rosemary. 1994. The Family and Family History 1500-1900. Themes in Comparitive History. London: Macmillan.

Orr, Clarissa Campbell, John Davis, Andreas Gestrich, Jonathan Petropolous, Torsten Riotte, John Rhl, Daniel Schnpflug, Matthew Seligmann, and Monika Wienfort. 2008. Royal Kinship. Anglo-German Family Networks 1815-1918. Berlin: Walter de Gruyter, vol. 4.

Rodriguez, Gregory. 2014. How Genealogy Became almost as Popular as Porn. In TIME.com. Available online: http:/ / time.com/133811/how-genealogy-became-almost-as-popular-as-porn/ (accessed on 24 November 2014).

Sahlins, Marshal. 2013. What Kinship Is-and Is Not. Chicago: University of Chicago Press.

Schneider, David Murray, ed. 1984. A Critique of the Study of Kinship. Ann Arbor: University of Michigan Press.

Schweitzer, Peter, ed. 2000. Dividends of Kinship: Means and Uses of Social Relatedness. European Association of Social Anthropologists. London: Routledge.

Segalen, Martine. 1986. Historical Anthropology of the Family. Translated by J. C. Whitehouse and Sarah Matthews. Cambridge: Cambridge University Press.

Shapiro, Warren. 2016. Why Schneiderian kinship studies have it all wrong. Structure and Dynamics: eJournal of Anthropological and Related Sciences 9: 218-39.

Susskind, Richard, and David Susskind. 2015. The Future of the Professions. Oxford: Oxford University Press.

Tadmor, Naomi. 2010. Early modern English kinship in the long run: Reflections on continuity and change. Continuity and Change 25: 15-48. [CrossRef]

Thomas, Rhodri, and Huw Thomas. 2014. 'Hollow from the start'? Professional associations and the professionalisation of tourism. The Service Industries Journal 34: 38-55. [CrossRef]

Wall, Richard. 2010. Economic collaboration of family members within and beyond households in English society, 1600-2000. Continuity and Change 25: 83-108. [CrossRef]

Watkins, Jeff. 1999. Educating professionals: The changing role of UK professional associations. Journal of Education and Work 12: 37-56. [CrossRef]

Wellman, Barry, and Kenneth Frank. 2001. Network capital in a multilevel world: Getting support from personal communities. Social Capital: Theory and Research, 233-73.

(c) 2018 by the author. Licensee MDPI, Basel, Switzerland. This article is an open access article distributed under the terms and conditions of the Creative Commons Attribution (CC BY) license (http://creativecommons.org/licenses/by/4.0/). 